\title{
The influence of thermal properties on power transmission characteristics of HVDC cables - a factor analysis
}

\author{
Björn Sonerud, Wendy Loyens \\ Borealis $\mathrm{AB}$
}

\begin{abstract}
Power transmission capacity of HVDC cable links depend to a large extent on the voltage level but also on operating temperature and consequently conductor cross-section. A high operating temperature offers larger transmission capacity at a given conductor crosssection. However, an increasing temperature will also increase the conductor loss and the associated costs. The most beneficial design choice is seldom straightforward and involves a trade-off between several design parameters. In this paper the influence of thermal properties of the insulating material and the surrounding soil, as well as operating temperature and conductor cross-section, is investigated by means of factor analysis with respect to important criteria such as transmission capacity, loss and associated cost of operation. This approach is chosen in order to separate different influencing factors as well as elucidating the interaction between said factors.
\end{abstract}

\section{Introduction}

In the last few years an increasing demand of interconnectivity and bulk transfer from renewable energy sources has sparked a boom in HVDC connections, which in Europe mainly has manifested in large scale cable installations. This development is not expected to decline. Today extruded DC-XLPE is qualified according to CIGRE TB496 up to $640 \mathrm{kV}$ offering further increase in power transfer capabilities of underground and submarine connections [1].

Europacable expects that $44600 \mathrm{~km}$ of transmission lines (also including overhead lines) will be commissioned until 2030 in Europe. Already during 2010-2014 $8000 \mathrm{~km}$ of HVAC and HVDC cables were installed globally. Of the HVDC connections a majority of the installed land connections use XLPE technology and for submarine HVDC cables the figures are roughly $50 \%$ XLPE and 50\% MI (mass impregnated paper cables) [2].

Such large investments come with technical, political and economic challenges. The construction of new overhead lines meets opposition from the public which can be avoided by using land cables. For submarine connections there are rarely any options but to use cables. Selecting cable and converter technology, installation methods and circuit topologies further contributes to the complex technical nature of these projects. To this one also needs to add an expected life of 40 years or more and the associated unpredictability of energy prices and emerging technologies in years to come.

Even looking at an isolated and highly simplified subset such as ampacity calculations of a high voltage cable according to IEC 60287 [3] complexity soon arises when aspects such as maximum operating temperature, thermal conductivity and conductor cross-section are taken into account - especially if both power transfer capabilities and life time cost are considered. One way of analyzing trade off situations which frequently occur is to use factor analysis where the relative strength of the influence of different parameters as well as their interaction can be studied.

\section{Method}

The approach adopted in this study is heavily influenced by the excellent paper by Pilgrim et al [4] where experimental design [5] is used as a basis for understanding the influence of different dielectric parameters on the ampacity of HVAC cables. In this study the power transfer capabilities as well as associated cost per unit of transmitted power in HVDC cable applications are considered. Naturally, the obvious way of increasing transmitted power is to increase the voltage level. However, this study focus on thermal properties such as maximum operating temperature, thermal conductivity of the insulation as well as the influence of laying conditions - i.e. the thermal conductivity of soil and the distance between a pair of cables in a bipole.

\subsection{IEC 60287 - assumptions}

Several assumptions are made in order to facilitate this study. First, as in [4], the methodology of IEC 60287 is used to calculate the ampacity. A generic HVDC cable bipole with unspecified insulation material is used. Second, when calculating the ampacity according to IEC 60287 thin layers of the cable (Figure 1), such as the semicon, jacket, lead sheath, armor and outer bedding are neglected with respect to the contribution to thermal resistance. This is motivated by the fact that said layers either have relatively good thermal conductivity (semicon, lead sheath and armoring) or are thin in comparison with the insulation (tapes and jacket). Third, the contribution of macroscopic resistive heating of the insulation is also neglected as it is small compared with the resistive losses in the conductor. 


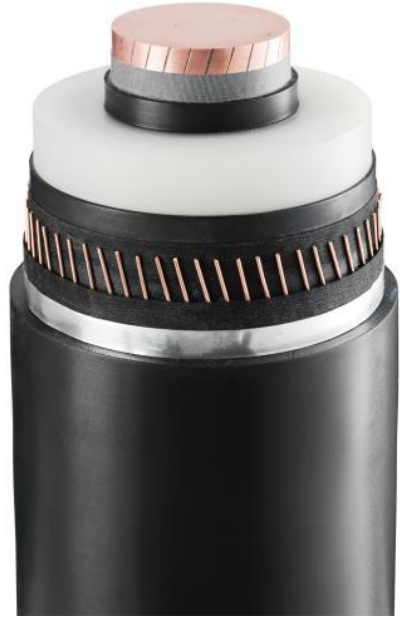

Figure 1: Extruded DC-XLPE land cable. In courtesy of NKT.

Making these assumptions a straight forward expression for the ampacity can be obtained from IEC 60287:

$\mathrm{I}=\left[\frac{\Delta \theta}{\mathrm{R}^{\prime}\left(\mathrm{T}_{1}+\mathrm{T}_{2}+\mathrm{T}_{3}+\mathrm{T}_{4}\right)}\right]^{0.5}$

$\mathrm{T}_{1}$ - thermal resistance between conductor and sheath

$\mathrm{T}_{2}$ - thermal resistance between sheath and armor

$\mathrm{T}_{3}$ - thermal resistance of external serving

$\mathrm{T}_{4}$ - thermal resistance of surrounding medium

$\mathrm{R}^{\prime}$ - $\mathrm{dc}$ resistance per unit length

$\Delta \theta$ - temperature difference vs ambient

I - current

In this study $T_{2}$ and $T_{3}$ are assumed to be negligible as mentioned above. Simplifying Equation (1) further while introducing the influence of temperature on the resistance of the conductor yields:

$\mathrm{I}=\left[\frac{\Delta \theta}{\mathrm{R}(1+\alpha \Delta \theta)\left(\mathrm{T}_{1}+\mathrm{T}_{4}\right)}\right]^{0.5}$

$\alpha-$ temperature coefficient of resistivity

$\mathrm{R}-\mathrm{dc}$ resistance at $20^{\circ} \mathrm{C}$ per unit length

The resistance needs to be further specified:

$\mathrm{R}=\frac{\rho}{\mathrm{A}}$

$\rho-$ resistivity of the conductor material

$\mathrm{A}$ - conductor area

Combining (2) and (3) gives the expression in Equation (4) which is the basis for the factor analysis:
$\mathrm{I}=\left[\frac{\mathrm{A} \Delta \theta}{\rho(1+\alpha \Delta \theta)\left(\mathrm{T}_{1}+\mathrm{T}_{4}\right)}\right]^{0.5}$

If a cost estimate is to be made both material cost and the losses over 40-year life need to be taken into account. Production, installation and maintenance cost are assumed not to be significantly affected by the parameters studied here. Material cost per unit length can be estimated using Equation (5) which only includes the conductor and insulation - these two materials comprise the most volume of cables in the EHV range:

$\mathrm{C}_{\mathrm{m}}=\mathrm{V}_{\mathrm{c}} \rho_{\mathrm{dc}} \mathrm{c}_{\mathrm{c}}+\mathrm{V}_{\mathrm{i}} \rho_{\mathrm{di}} \mathrm{c}_{\mathrm{i}}$

$\mathrm{V}_{\mathrm{c}}$ and $\mathrm{V}_{\mathrm{i}}$ - volume of conductor and insulation respectively per unit length

$\rho_{\mathrm{dc}}$ and $\rho_{\mathrm{di}}-$ density of conductor and insulation respectively

$\mathrm{c}_{\mathrm{c}}$ and $\mathrm{c}_{\mathrm{i}}-$ cost per kilo of conductor and insulation material respectively

The cost per unit length associated with the resistive loss can be described as

$\mathrm{C}_{1}=\mathrm{I}^{2} \frac{\rho(1+\alpha \Delta \theta)}{\mathrm{A}} \mathrm{Lc}_{\mathrm{e}}$

$\mathrm{L}$ - estimated lifetime of the cable

$c_{e}-$ cost per energy unit

\subsection{Parameters}

Through an initial screening of parameters it was found that insulation thickness and insulation conductivity was of marginal importance with respect to ampacity and cost. Thus, operating temperature $\left(20^{\circ} \mathrm{C}+\Delta \theta\right)$, thermal conductivity of the insulation (underlying $\mathrm{T}_{1}$ ), equivalent thermal resistance resulting from installation conditions $\left(\mathrm{T}_{4}\right)$ as well as conductor area (A) were chosen for in depth study. Three symmetric levels of parameter values representing typical design ranges for HVDC cables are shown in Table 1. Three levels are used in order to capture quadratic relationships.

Table 1. Parameter values

\begin{tabular}{|c|c|c|c|c|}
\hline & $\begin{array}{c}{[\mathrm{A}]} \\
\text { Thermal } \\
\text { resistance } \\
\mathrm{T}_{4}[\mathrm{~K} / \mathrm{W}]\end{array}$ & $\begin{array}{c}{[\mathrm{B}]} \\
\text { Operating } \\
\text { temperature } \\
{\left[{ }^{\circ} \mathrm{C}\right]}\end{array}$ & $\begin{array}{c}{[\mathrm{C}]} \\
\text { Thermal } \\
\text { conductivity } \\
{[\mathrm{W} /(\mathrm{mK})]}\end{array}$ & $\begin{array}{c}{[\mathrm{D}]} \\
\text { Conductor } \\
\text { area } \\
{\left[\mathrm{mm}^{2}\right]}\end{array}$ \\
\hline L1 & 0.5 & 50 & 0.15 & 1600 \\
\hline L2 & 0.7 & 70 & 0.3 & 2000 \\
\hline L3 & 0.9 & 90 & 0.45 & 2400 \\
\hline
\end{tabular}




\subsection{Analysis}

In order to investigate the influence of the different parameters on the power transfer capabilities and the power loss a full factorial of Table 1 is generated $\left(3^{4}=81\right)$ as shown schematically in Table 2 - referred to as the main effect contrast. This amounts to calculating the ampacity for each possible combination in Table 1 to identify the relative influence of each parameter. The advantage of expressing the full factorial as in Table $2 b$ as well as using equally spaced parameters in Table 1 is that interaction contrasts can be generated in a straightforward manner. An example is shown in Table 3 where the interaction contrast between parameter A (thermal resistance) and B (operating temperature) is generated by simply multiplying $[\mathrm{A}]$ and [B]. In addition quadratic contrasts that correspond to the non-linearity of the system can be generated.

By using the contrast matrices the impact of each parameter on the studied result, e.g. ampacity, can be established. The relative importance of different parameters can also be studied if the results are normalized and presented in a Daniel plot (described in detail in [4]).

\section{Results}

Two important aspects of the selection of cable technology and design are the ampacity (proportional to amount of power transferred) and associated cost per unit power transferred. Looking at the Daniel plot in Figure 2 it can be seen that four items stand out as the most important for the ampacity - the main parameters listed in Table 1. This indicates that interactions and non-linarites are weak in this system and can be neglected in further analysis. The most influential parameter for increasing ampacity is, not surprisingly, the operating temperature [B]. Increasing the conductor cross-section [D] and using an insulating material with a large thermal conductivity [C] is also beneficial.

Table 2. Full factorial

\begin{tabular}{|c|c|c|c|}
\hline$[\mathrm{A}]$ & {$[\mathrm{B}]$} & {$[\mathrm{C}]$} & {$[\mathrm{D}]$} \\
\hline L1 & $\mathrm{L} 1$ & $\mathrm{~L} 1$ & $\mathrm{~L} 1$ \\
\hline L2 & $\mathrm{L} 1$ & $\mathrm{~L} 1$ & $\mathrm{~L} 1$ \\
\hline L3 & $\mathrm{L} 1$ & $\mathrm{~L} 1$ & $\mathrm{~L} 1$ \\
\hline $\mathrm{L} 1$ & $\mathrm{~L} 2$ & $\mathrm{~L} 1$ & $\mathrm{~L} 1$ \\
\hline $\mathrm{L} 2$ & $\mathrm{~L} 2$ & $\mathrm{~L} 1$ & $\mathrm{~L} 1$ \\
\hline $\mathrm{L} 3$ & $\mathrm{~L} 2$ & $\mathrm{~L} 1$ & $\mathrm{~L} 1$ \\
\hline$\cdots$ & $\cdots$ & $\cdots$ & $\cdots$ \\
\hline$\cdots$ & $\cdots$ & $\cdots$ & $\cdots$ \\
\hline$\cdots$ & $\cdots$ & $\cdots$ & $\cdots$ \\
\hline L3 & $\mathrm{L} 3$ & $\mathrm{~L} 3$ & $\mathrm{~L} 3$ \\
\hline
\end{tabular}

\begin{tabular}{|c|c|c|c|}
\multicolumn{5}{|c|}{ b. } \\
\hline$[\mathrm{A}]$ & {$[\mathrm{B}]$} & {$[\mathrm{C}]$} & {$[\mathrm{D}]$} \\
\hline-1 & -1 & -1 & -1 \\
\hline 0 & -1 & -1 & -1 \\
\hline 1 & -1 & -1 & -1 \\
\hline-1 & 0 & -1 & -1 \\
\hline 0 & 0 & -1 & -1 \\
\hline 1 & 0 & -1 & -1 \\
\hline$\ldots$ & $\cdots$ & $\cdots$ & $\cdots$ \\
\hline$\ldots$ & $\cdots$ & $\cdots$ & $\cdots$ \\
\hline$\ldots$ & $\cdots$ & $\cdots$ & $\cdots$ \\
\hline 1 & 1 & 1 & 1 \\
\hline
\end{tabular}

Table 3 .

\begin{tabular}{|c|c|c|}
\hline$[\mathrm{A}]$ & {$[\mathrm{B}]$} & {$[\mathrm{A}] \mathrm{x}[\mathrm{B}]$} \\
\hline-1 & -1 & 1 \\
\hline 0 & -1 & 0 \\
\hline 1 & -1 & -1 \\
\hline-1 & 0 & 0 \\
\hline 0 & 0 & 0 \\
\hline 1 & 0 & 0 \\
\hline$\cdots$ & $\cdots$ & $\cdots$ \\
\hline$\cdots$ & $\cdots$ & $\cdots$ \\
\hline$\cdots$ & $\cdots$ & $\cdots$ \\
\hline 1 & 1 & 1 \\
\hline
\end{tabular}

Increased thermal resistance of the surroundings of the cable [A] will reduce the ampacity. None of this is surprising and can readily be observed in Equation (4). The cost per transferred unit power constitutes a more complex relationship as e.g. increasing the conductor cross-section will reduce the loss over time but increase the material cost of the cable. As can be seen in Figure 3 the same four parameters listed in Table 1 are still the most important. Interaction effects and non-linearities are also in this case small enough to be neglected. The factor most increasing the cost per transferred power unit is by far the operating temperature [B] followed by the thermal conductivity of the insulation [C]. Conductor cross-section [D] and increased thermal resistance of the ground [A] contribute to a decrease in cost.

\section{Discussion}

It seems contradictory that increasing thermal conductivity [C] and operating temperature [B] will increase the total cost when it effectively will increase

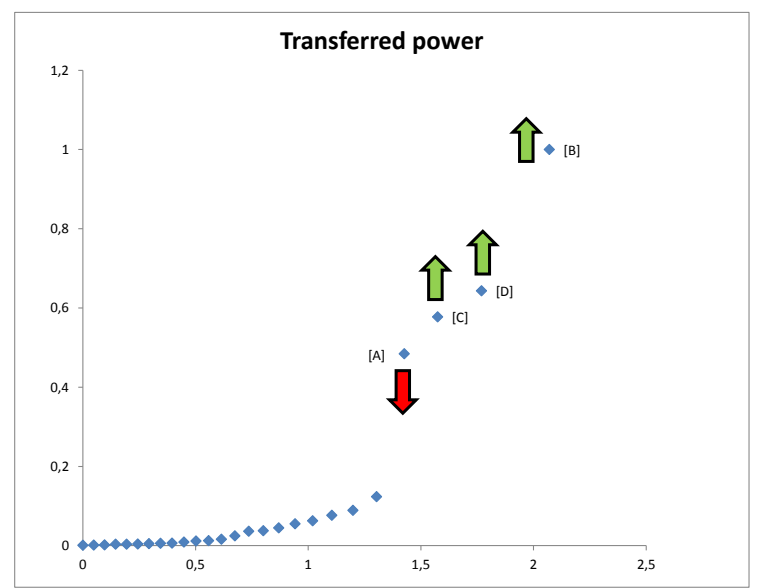

Figure 2: Normalized power transferred. 


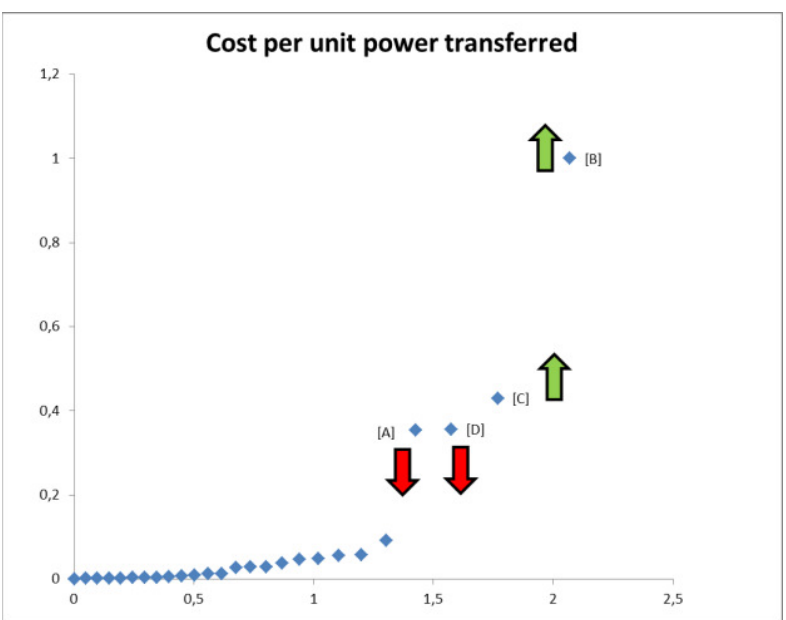

Figure 3: Normalized cost per unit power transferred based on associated cost of losses and material.

the ampacity as seen in Figure 2. However, the explanation for this is straight forward; considering a 40-year life the cost associated with resistive loss during operation will completely dominate over the initial investment of the cable. In a similar fashion, increasing conductor cross-section [D] will reduce the total cost despite being a significant contributor to the initial material cost. Thus, increasing the ampacity by any other means than reducing the conductor resistance will also increase the total cost as a larger current will flow through the cable:

$$
\mathrm{P}_{\text {loss }}=\frac{\rho(1+\alpha \Delta \theta)}{\mathrm{A}} \mathrm{I}^{2}
$$

$\mathrm{P}_{\text {loss }}$ - power loss in cable

$\rho-$ resistivity of the conductor material

A - conductor area

$\alpha$ - temperature coefficient of resistivity

$\Delta \theta$ - temperature difference vs ambient

From a theoretical point of view the conclusion would be that the cable conductor cross-section should be maximized when total cost over life is considered. However, in practice there are several limiting factors regarding conductor cross-section. Cable manufacturing lines are limited in the diameter of cables which can be produced. A large conductor cross-section also influences the number of joints as well as the weight of the cable - two factors which complicate the installation process. If conductor size is considered a fixed parameter two means of increasing the ampacity and power transfer capability by modifying the cable design are:

(1) Using insulating materials with higher thermal conductivity

(2) Increasing the maximum operating temperature

As highlighted in Equation (7) increasing the ampacity by increasing the operating temperature (increasing both I and $\Delta \theta$ ) contributes more to the losses than an

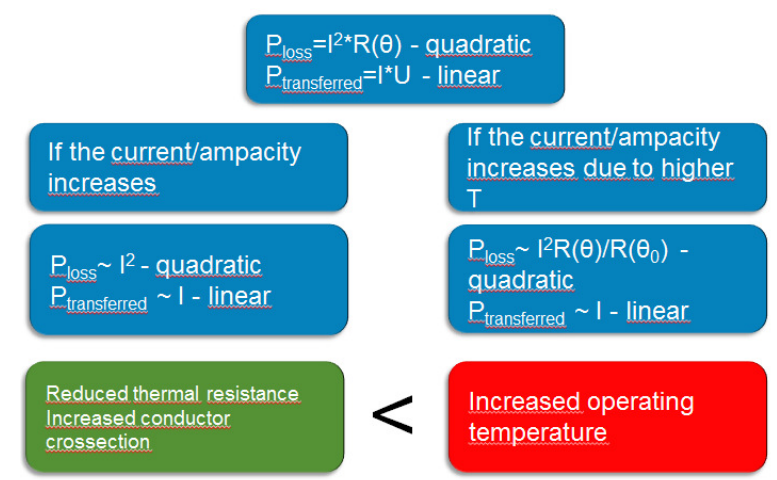

Figure 4: Consequences of increased operating temperature compared with increased conductor crosssection and thermal resistance

improvement in thermal conductivity (increasing only I). This is described in an alternative way in the two parallel branches in Figure 4 where it can be seen that increasing the ampacity by reduced thermal resistance of the insulating layer or increasing the conductor crosssection will contribute less to the losses than increased operating temperature.

\section{Conclusions}

Factor analysis is a useful tool when investigating the relative importance of parameters. In this particular case ampacity and cost per transferred unit power has been studied but the method can be expanded and detailed further. The results provide a theoretical basis for different design choices but practical limitations of manufacturing, installation and operation must of course be taken into account as well. From the limited study presented here conductor cross-section, operating temperature and thermal conductivity of the insulation stands out as important factors. Increasing the conductor cross-section has the advantage of increasing the ampacity without increasing the operating temperature. This is beneficial as the main cause of losses is the resistance of the conductor which is strongly temperature dependent. As the conductor size cannot be increased indefinitely in practice, an insulating material with high thermal conductivity is desirable as well.

\section{References}

[1] Borealis (2017), Borlink ${ }^{\mathrm{TM}}$ extruded high voltage direct current technology sets new record at 640 kilovolt, http://www.borealisgroup.com/en/company/newsevents/news/2017/4/borlink-extruded-highvoltage-direct-current-technology-sets-new-recordat-640-kilovolt/ Accessed 2017-04-10.

[2] Europacable (2017), Electricity Transmission of Tomorrow - Underground and Subsea cables in Europe, 
http://www.europacable.com/books/electricity tra nsmission.html

Accessed 2017-03-21

[3] IEC 60287-1-1:2006, Electric cables - Calculation of the current rating, 2006.

[4] Pilgrim, J.A., Lewin, P.L. and Vaughan, A.S., Quantifying the Operational Benefits of New HV Cable Systems in terms of Dielectric Design Parameters, Conference Record of the 2012 IEEE International Symposium on Electrical Insulation (ISEI), 2012.

[5] Grove, D.M., and Davis, T.P. Engineering Quality \& Experimental Design, 1997. 